\title{
Numerical And Experimental Analysis of Temperature Distribution And Melt Flow In Fiber Laser Welding of Inconel 625
}

Iskander Tlili

Al-Zulfi, Majmaah University

Dumitru Baleanu ( $\nabla$ dumbaleanu@gmail.com )

Cankaya University

S. Mohammad Sajadi

Cihan University-Erbil

Ferial Ghaemi

Universiti Kebangsaan Malaysia (UKM)

\section{Research Article}

Keywords: laser welding, superalloy, temperature distribution, microstructure, mechanical properties

Posted Date: October 18th, 2021

DOl: https://doi.org/10.21203/rs.3.rs-982749/v1

License: (c) (i) This work is licensed under a Creative Commons Attribution 4.0 International License. Read Full License 


\title{
Numerical and experimental analysis of temperature distribution and melt flow in fiber laser welding of Inconel 625
}

\author{
Iskander Tlili $^{1}$, Dumitru Baleanu ${ }^{2,3,4, *}$, S. Mohammad Sajadi ${ }^{5,6}$, Ferial Ghaemi ${ }^{7}$ \\ 1-Physics Department, College of Science, Al-Zulfi, Majmaah University, AL-Majmaah 11952, \\ Saudi Arabia \\ 2-Department of Mathematics, Faculty of Arts and Sciences, Cankaya University, Ankara, \\ Turkey \\ 3- Institute of Space Sciences, Magurele, Romania \\ 4-Department of Medical Research, China Medical University Hospital, China Medical \\ University, Taichung, Taiwan \\ 5- Department of Nutrition, Cihan University-Erbil, Kurdistan Region, Iraq \\ 6- Department of Phytochemistry, SRC, Soran University, KRG, Iraq \\ 7- Department of Chemical and Process Engineering, Faculty of Engineering and Built \\ Environment, Universiti Kebangsaan Malaysia (UKM), 43600, Bangi, Selangor, Malaysia \\ * Corresponding author \\ Email: dumbaleanu@gmail.com
}

\begin{abstract}
In these days, laser is a useful and valuable tool. Low input heat, speed, accuracy, and high controllability of laser welding have led to widespread use in various industries. Nickel-based superalloys are creep-resistant materials used in high-temperature conditions. Also, these alloys have high strength, fatigue, and suitable corrosion resistance. Inconel 625 is a material that is strengthened by a complex deposition mechanism. Therefore, the parameters related to laser welding affect the microstructure and mechanical properties. Therefore, in this study, the effect of fiber laser welding parameters on temperature distribution, weld bead dimensions, melt flow
\end{abstract}


velocity, and microstructure was investigated by finite volume and experimental methods. In order to detect the temperature history during continuous laser welding, two thermocouples were considered at a distance of $2 \mathrm{~mm}$ from the welding line. The heat energy from the laser beam was modeled as surface and volumetric heat flux. The results of numerical simulation showed that Marangoni stress and buoyancy force are the most important factors in the formation of the flow of liquid metal. Enhancing the laser power to $400 \mathrm{~W}$ led to the expansion of the width of the molten pool by $1.44 \mathrm{~mm}$, which was in good agreement with the experimental results. Experimental results also showed that increasing the temperature from $500{ }^{\circ} \mathrm{C}$ around the molten pond leads to the formation of a coarse-grained austenitic structure.

Keywords: laser welding; superalloy; temperature distribution; microstructure; mechanical properties

\section{Introduction}

Humans have long made various devices and equipment due to the desire to have a comfortable life. To build a complex mechanism, the need to connect different components has always been felt. In the past, due to lack of resources and sufficient knowledge in the use of resources, equipment, and technology used to connect materials has been very simple. However, over time, various methods of permanent and temporary connection emerged. One of the most essential methods used to connect parts permanently is welding and soldering. Various methods for welding parts have been proposed in recent years. However, with the advancement of technology in recent years, the use of high-power laser beams has been considered by researchers and artisans [1]. The laser welding method is suitable for welding various components due to the smaller heat-affected zone (HAZ), minimal thermal-mechanical distortion, low heat input, and good focusing characteristics. Also, reviewing the researchers' results in recent years, it is clear that the quality of laser welding depends on various process parameters such as laser power, pulse duration, frequency, focal length, and welding speed [2, 3]. Also, the type of parts used in the laser welding process is very essential. One of the most widely used materials in recent years in all automotive, aerospace, food, oil and gas industries, and pollution control equipment is Inconel superalloys [4-6]. One of the most important and widely used Inconel superalloys is Inconel 625. This metal has excellent resistance to corrosion at high temperatures and acidic 
environments. It is also a suitable metal for welding due to its unique mechanical properties [7]. In recent years, the study of metal bonding by numerical and experimental methods in the laser welding process has always been of interest to researchers [8-10].

Azari et al. [11] analyzed the temperature distribution and fusion zone microstructure in an Inconel 625 superalloy laser welding. The findings indicated that the temperature distribution changes of laser parameters such as welding speed, nozzle distance, beam displacement, and laser power, which led to a change in the molten pool's depth and width. It was also found that increasing the power of the laser has a significant effect on increasing the temperature. Faraji et al. [12] investigated heat and mass transfer using numerical modeling of fluid flow in a dissimilar laser welding process of Ti6Al4V and Inconel 718. The findings proved that the proposed numerical model has a good agreement with experiments. Madhankumar et al. [13] analyzed the laser welding parameters' effect on the tensile strength of Inconel 718 and duplex 2205 stainless steel alloys. By examining the laser parameters, the desired ultimate tensile strength was obtained from the analysis of variance to gain the weld connection optimization. Thejasree et al. [14], in an experimental-numerical study, investigated the laser welding parameters effect on the molten pool and welding geometry of Inconel 625. With the simulation performed by SYSWELD software, it was found that the experimental and simulation results are very close according to the thermal, microstructural, and mechanical analysis. The effect of laser power and welding time was also reported as effective parameters. Ahmad et al. [15], in the fiber laser welding process of duplex 2205 and Inconel 625 alloys, investigated the effect of different heat inputs on the microstructure and welding geometry of the welding area. The results showed that by reducing the energy input, the molten pool's width was reduced, and the mechanical properties of the joint area were improved. In a laser welding process, Voropaev et al. [16] investigated the effects of heat treatment on Inconel 718 alloy. The results showed a significant effect of heat treatment on the weld metal structure and complete phase transformations occurred. Srikanth et al. [17], in a laser welding process, studied the welding heat effect on the microstructure of Inconel 625. The results of the microstructure study in the fusion zone showed that the grain size was affected by the welding heat and the laser power. Cheepu et al. [18], in a laser welding process, investigated the effect of laser parameters on the mechanical properties of high tensile steel and Inconel 718. The results illustrated that laser power had a significant effect on the strength and weld's mechanical properties. In a laser welding process, Sharma et al. [19] 
surveyed the laser parameters' effect on the melting zone. The results indicated that the height of the surface reinforcement and the surface of the weld melting zone decreased with increasing scanning speed.

Ramkumar et al. [20] obtained the optimal process parameters for laser welding of Inconel alloy 718 alloys and martensitic stainless steel. The outcomes showed that by using the desired welding speed $(1500 \mathrm{~mm} / \mathrm{min})$, a fusion zone without porosity and an ideal keyhole could be achieved. Mishra et al. [21] investigated the joint area's microstructure and mechanical properties of Inconel 625 and S.S 316 in a laser welding process. The results illustrated that the microstructure of the weld zone near Inconel 625 was columnar dendrites, while near the S.S 316, metal was predominantly cellular. Li et al. [22] evaluated the quality of laser welding performed by fiber laser on Inconel 718. The results indicated that the welding quality and appearance could be bright and smooth by reducing the ambient pressure. Also, the study of plasma distribution proved that a smaller area of plasma led to an increase in the laser energy absorption efficiency, which ultimately led to an increase in the depth of penetration. Hernando et al. [23] developed a numerical model for predicting weld geometry and joint area microstructure of Inconel 718 in the laser welding process. The results proved that there was a good agreement between the experimental model and the proposed numerical model, and the most important parameters affecting the welding were the laser power and feed rate. In another study, Hernando et al. [24] simulated and predicted the parameters affecting the welding of Inconel 718 alloy concerning the wobbling strategy. This strategy showed that a wide range of welds could be covered by combining elliptical and linear motions. Jelokhani et al. [25] investigated the optimal parameters of the Inconel 625 laser welding process using the response surface method (RSM). The finding indicated that the maximum welding strength was obtained when the values of laser power, laser speed, and spot size were $260 \mathrm{~W}, 1.2 \mathrm{~mm} / \mathrm{s}$, and $180 \mu \mathrm{m}$, respectively. Ebrahimi et al. [26] used the Gaussian optics theory to investigate the thermal effects of Inconel 625 and 316 stainless steel welding in keyhole formation. The results illustrated that this volumetric model was suitable for simulating heat flux profiles and could depict the actual conditions well. Janasekaran et al. [27] evaluated the effect of overlap factor and laser welding speed on the laser welding of Inconel 600 and Ti6Al4V. The results indicated that the optimal parameters to achieve a suitable strength were equal to an overlap factor of $50 \%$, speed of welding of $40 \mathrm{~mm} / \mathrm{s}$, and laser welding power of $250 \mathrm{~W}$. Ren et al. [28] conducted a 
comparative study between $\mathrm{CO}_{2}$ laser welding methods and fiber laser welding of Inconel 617 alloy. The outcomes illustrated that to achieve a complete melting penetration in the welding process, fiber laser was more efficient, and the appearance of the weld bead geometry was also different.

By examining the effect of continuous wave laser welding parameters on the temperature gradient in the molten pool, the thermal stress in the workpiece can be controlled, and the possibility of thermal fatigue can be reduced. For this purpose, in this study, an experimental and numerical study of Inconel 625 sheet laser welding was conducted. Due to the significant effect of melt flow and shear stress caused by Marangoni flow on the temperature gradient and dimensions of the weld bead, the finite volume method was used to discretize the conservation equation.

\section{Experimental procedure}

Fiber laser at Continuous mode with a maximum nominal output power of 500W and Raytools BW240 laser welding head with copper side delivery gas nozzle was used for welding experiments. Argon gas at a constant pressure of 35 psi was blew to the welding area to protect the welding region. The temperature measuring at the location of $2 \mathrm{~mm}$ away from the laser beam's center was done by K-type thermocouples. The materials of welding were Inconel 625 with $1.5 \mathrm{~mm}$ thickness. The Olympus optical microscope under the ASTM E883-11 standard was used for microstructure images metallurgical analysis preparation. The samples were etched under ASTM E3-11 standard, and the microstructure was analyzed with TESCAN MIRA3 FESEM. The sample's material chemical properties are illustrated in Table 1.

Table 1. Chemical composition of Inconel 625 [11].

\begin{tabular}{cccccccccccccc}
\hline Composition & $\mathrm{C} \%$ & $\mathrm{Nb} \%$ & $\mathrm{Cr} \%$ & $\mathrm{Nb} \%$ & $\mathrm{Mn} \%$ & $\mathrm{Fe} \%$ & $\mathrm{Ti} \%$ & $\mathrm{Si} \%$ & $\mathrm{Mo} \%$ & $\mathrm{~V} \%$ & $\mathrm{Si} \%$ & $\mathrm{~W} \%$ & $\mathrm{Ni} \%$ \\
\hline \multirow{2}{*}{ Weight } & 0.082 & 3.5 & 22.85 & 3.5 & 0.11 & 4.81 & 0.19 & 0.1 & 8.1 & 0.01 & 0.1 & 0.014 & 59.6
\end{tabular}

\section{Numerical Simulation}


The temperature gradient and liquid metal's flow in the molten pool have a direct relation with the quality and mechanical properties of the welded metal. Therefore, predicting the parameters affecting the heat transfer and fluid flow can increase the welding quality and reduce the costs. In order to numerical simulation of continuous laser welding, a finite volume transient numerical model was used. A numerical code was also used to define the thermal model and the thermophysical properties with temperature variation. The number of grid elements after the grid study was considered to be 421875 . Fig. 1 showed a schematic of the laser welding process and the dimensions of the pieces. In order to investigate the various laser welding parameters and validate the results, the time history of temperature, according to fig. 1, was obtained around the center of the beam.

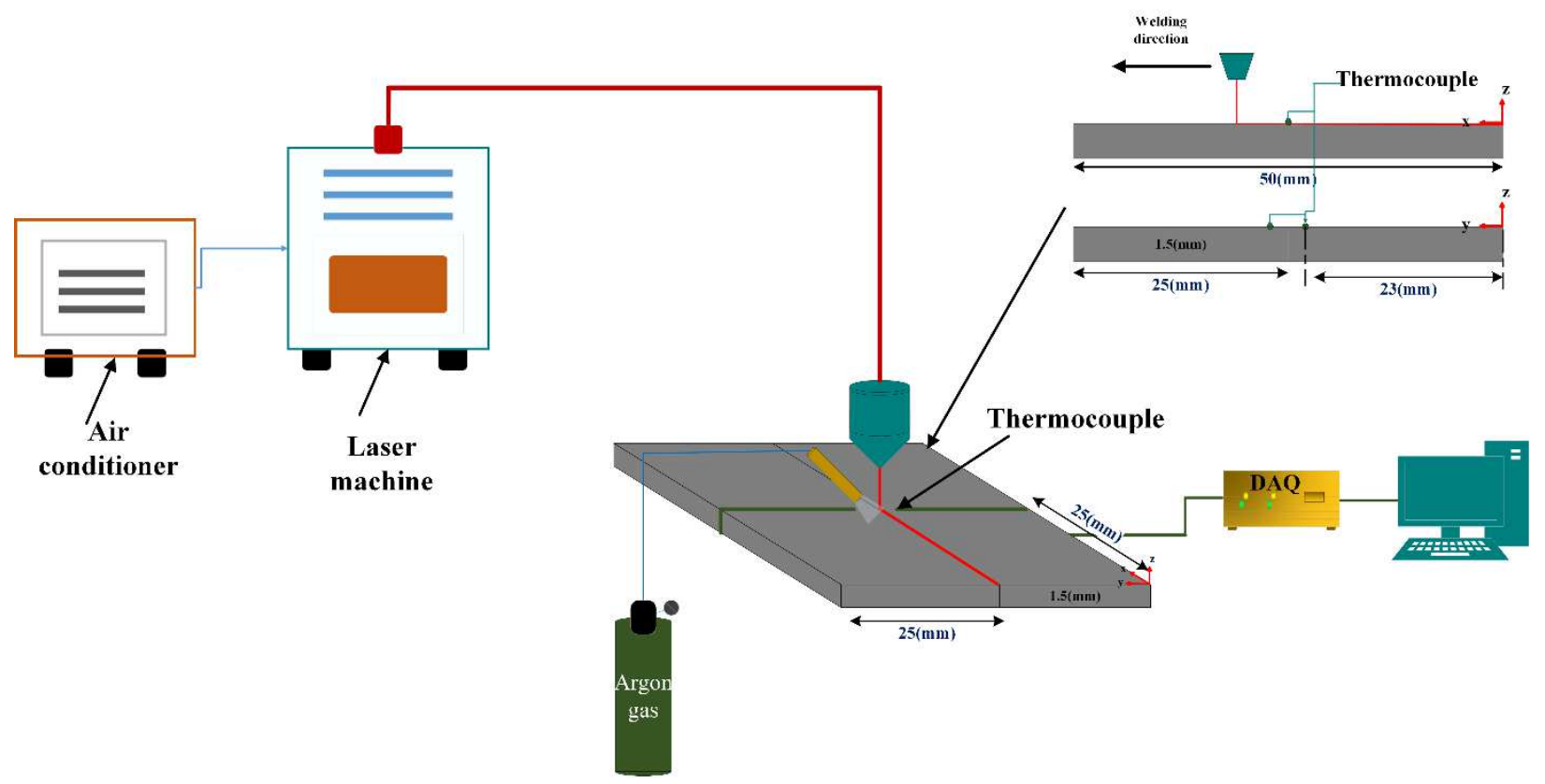

Fig. 1. Schematic configuration of the laser welding process.

\subsection{Governing equations}

The discretization of the equations was considered according to these assumptions:

- The flow of fluid was considered incompressible, Newtonian, and laminar.

- The molten pool's surface was considered flat.

- Vaporization of liquid metal was ignored. 
- The initial temperature of $25^{\circ} \mathrm{C}$ was considered.

Gaussian heat source and heat flux was utilized to simulate the absorbed energy. Fig. 2 showed the parameters and a schematic of the thermal model.

a)

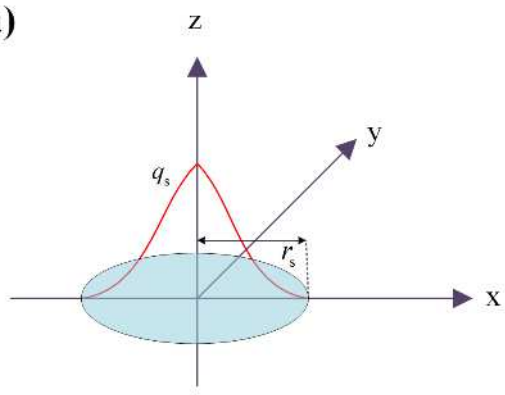

b)

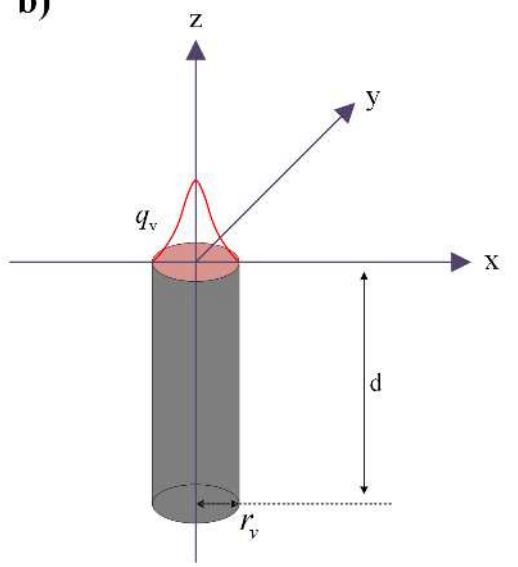

Fig. 2. Configuration of thermal modes a) heat flux, b) cylindrical heat source.

The equations for the Gaussian heat flux and heat source shown in fig. 2 are as follows [29, 30].

$$
\begin{aligned}
& q_{s}(x, y)=\frac{3 f_{1} \eta p}{\pi r_{s}^{2}} \exp \left(-3 \frac{\left(x^{2}+y^{2}\right)}{r_{s}^{2}}\right) \\
& q_{v}(x, y, z)=\frac{6 f_{2} \eta p}{\pi r_{v}^{2} d} \exp \left(-3 \frac{\left(x^{2}+y^{2}\right)}{r_{v}^{2}}\right)\left(\frac{m z+r_{v}}{m d+2 r_{v}}\right)
\end{aligned}
$$

In Eqs. 1 and 2, $q_{s}, q_{v}, p$ and $f_{1}, f_{2}$ are the surface heat flux, cylindrical volumetric heat flux, laser power, and energy distribution coefficients, respectively. Also, $d$ indicates the height of the heat source, $r_{s}$ is the radius of Gaussian heat flux, $r_{v}$ is the radius of the cylindrical heat source, $\mathrm{m}$ is the coefficient of Gaussian damping, and $\eta$ is the coefficient of absorption.

Continuity equation:

$$
\frac{\partial \rho}{\partial t}+\nabla \cdot(\rho U)=0
$$

Momentum equation:

$$
\frac{\partial(\rho \vec{U})}{\partial t}+\nabla \cdot(\rho \vec{U} \vec{U})=-\nabla \mathrm{p}+\nabla \cdot(\mu \nabla \vec{U})+\rho \vec{g}-\frac{\mu}{K}(\vec{U})
$$

Energy equation: 


$$
\frac{\partial(\rho H)}{\partial t}+\nabla \cdot(\rho \vec{U} H)=\nabla \cdot(k \nabla T)+q
$$

Where $\rho, H, t, p, \vec{U}, k, \vec{g}, K$ and $\mu$ are density, total enthalpy, time, pressure, vector of velocity, coefficient of thermal conductivity, gravity acceleration, coefficient of Darcy resistance and dynamic viscosity, respectively.

\subsection{Boundary conditions}

The boundary condition at the surface:

$$
k \frac{\partial T}{\partial \vec{n}}=-\varepsilon \sigma\left(T^{4}-T_{\infty}^{4}\right)-h\left(T-T_{\infty}\right)+q_{s}
$$

Where $\varepsilon$ is the coefficient of emission, $\sigma$ is the coefficient of Stefan-Boltzmann, $T_{\infty}$ is the surrounding temperatures, and $\mathrm{h}$ is the coefficient of convection heat transfer.

Shear stress due to surface tension gradient:

$$
\begin{aligned}
& \mu \frac{\partial u}{\partial z}=-\frac{\partial \gamma}{\partial T} \frac{\partial T}{\partial x} \\
& \mu \frac{\partial v}{\partial z}=-\frac{\partial \gamma}{\partial T} \frac{\partial T}{\partial y}
\end{aligned}
$$

The boundary condition on the lower and lateral surfaces was expressed as follow:

$$
k \frac{\partial T}{\partial \vec{n}}=-\varepsilon \sigma\left(T^{4}-T_{\infty}^{4}\right)-h\left(T-T_{\infty}\right)
$$

\subsection{Thermophysical properties}

High-temperature variations during laser welding of Inconel alloy 625 lead to significant changes in thermophysical properties. Therefore, the correct determination of the properties of the considered material could lead to accurate modeling of the laser welding process. For this 
purpose, some thermophysical properties as a function of temperature were shown in fig. 3. Also, other thermophysical properties are listed in Table 2.

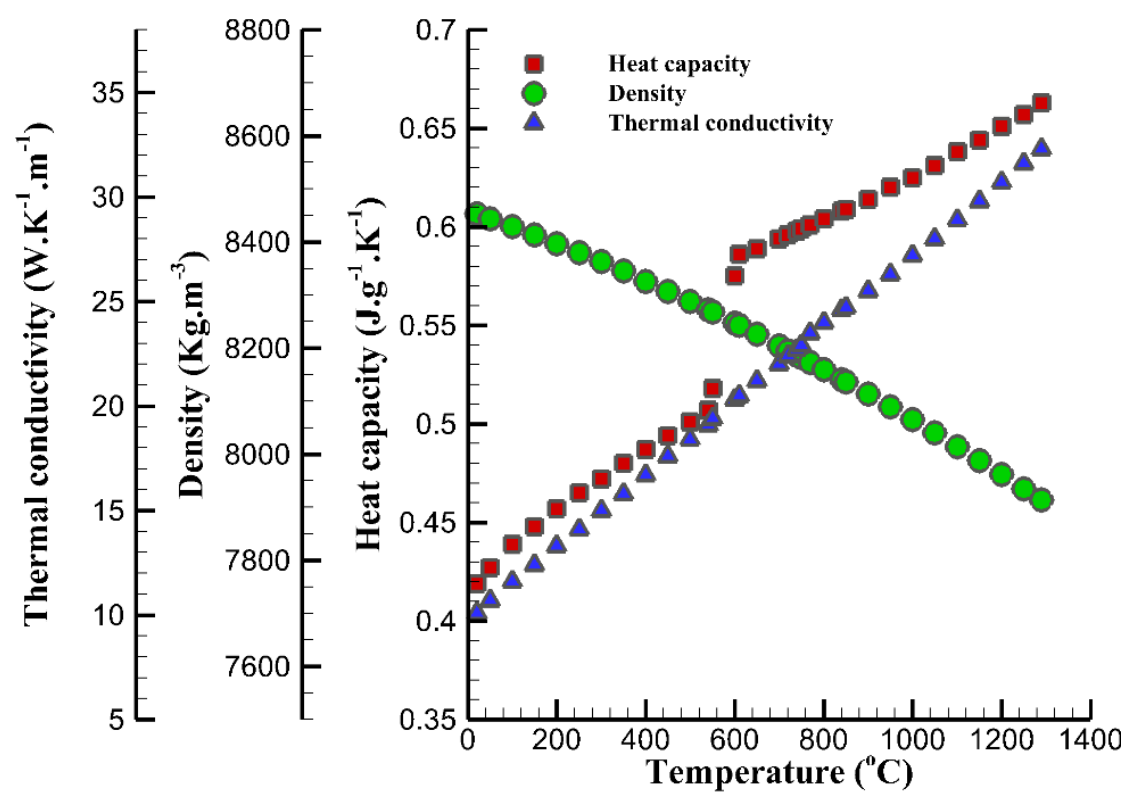

Fig. 3. Thermophysical properties as a function of temperature [33-35].

Table 2. Thermophysical properties of Inconel 625 [33-40].

\begin{tabular}{cccc}
\hline Nomenclature & Symbol & Value & Unit \\
\hline Solidus temperature & $\mathrm{T}_{\mathrm{s}}$ & 1563 & $\mathrm{k}$ \\
Liquidus temperature & $\mathrm{T}_{\mathrm{l}}$ & 1623 & $\mathrm{k}$ \\
Ambient temperature & $T_{\infty}$ & 298 & $\mathrm{k}$ \\
Melting latent heat & $\mathrm{L}_{\mathrm{m}}$ & $227 \times 10^{5}$ & $\mathrm{~J} \mathrm{~kg}^{-1}$ \\
Surface tension gradient & $\mathrm{A}_{\sigma}$ & -0.00011 & $\mathrm{~N} \mathrm{~m}^{-1} \mathrm{k}^{-1}$ \\
Stefan-Boltzmann constant & $\sigma$ & $5.67 \times 10^{-8}$ & $\mathrm{~W} \mathrm{~m}^{-2} \mathrm{k}^{-4}$ \\
Dynamic viscosity & $\mu$ & 0.0072 & $\mathrm{~kg} \mathrm{~m}^{-1} \mathrm{~s}^{-1}$ \\
\hline
\end{tabular}

\section{Results and Discussions}

After discretizing the continuity, momentum, and energy governing equations as a finite volume method and considering the suitable heat flux and boundary conditions, three-dimensional modeling of the welding speed effect and laser power on the temperature distribution, velocity 
and weld bead dimension was done. The considered parameters to investigate the temperature history, velocity, and fusion zone during the continuous wave laser welding process are given in Table 3. In all cases, the focal position was considered at the surface of the pieces.

Table 3. Laser welding parameters for numerical simulation.

\begin{tabular}{ccc}
\hline Sample & $\begin{array}{c}\text { Welding Speed } \\
(\mathrm{mm} / \mathrm{min})\end{array}$ & $\begin{array}{c}\text { Power } \\
(\mathrm{W})\end{array}$ \\
\hline 1 & 300 & 350 \\
\hline 2 & 400 & 350 \\
\hline 3 & 500 & 350 \\
\hline 4 & 300 & 300 \\
\hline 5 & 300 & 400 \\
\hline
\end{tabular}

\subsection{Temperature distribution}

Predicting the temperature distribution and HAZ can help to control the primary microstructure. Hence, the temperature history was obtained at different welding speeds and laser powers. Fig. 4 showed the time history of temperature at different welding speeds within $2 \mathrm{~mm}$ of the center of the beam. As can be seen, with increasing the speed of movement of the thermal model due to the reduction of power density absorption time, the temperature decreased significantly. So that with increasing the speed of movement laser head from 300 to $500 \mathrm{~mm} / \mathrm{min}$, the temperature decreased by approximately $160{ }^{\circ} \mathrm{C}$. Also, the results obtained from numerical simulations were in good agreement with the results of experiments, which indicated the correct determination of the Gaussian heat source and heat flux and thermophysical properties. Fig. 5 indicated the temperature variation versus time at different laser powers. It can be concluded that, with enhancing the laser power by $100 \mathrm{~W}$, the maximum temperature around the fusion zone increased by about $120{ }^{\circ} \mathrm{C}$ due to the enhanced power density. It is also concluded that by enhancing the power density, the maximum temperature was obtained at a higher time. 


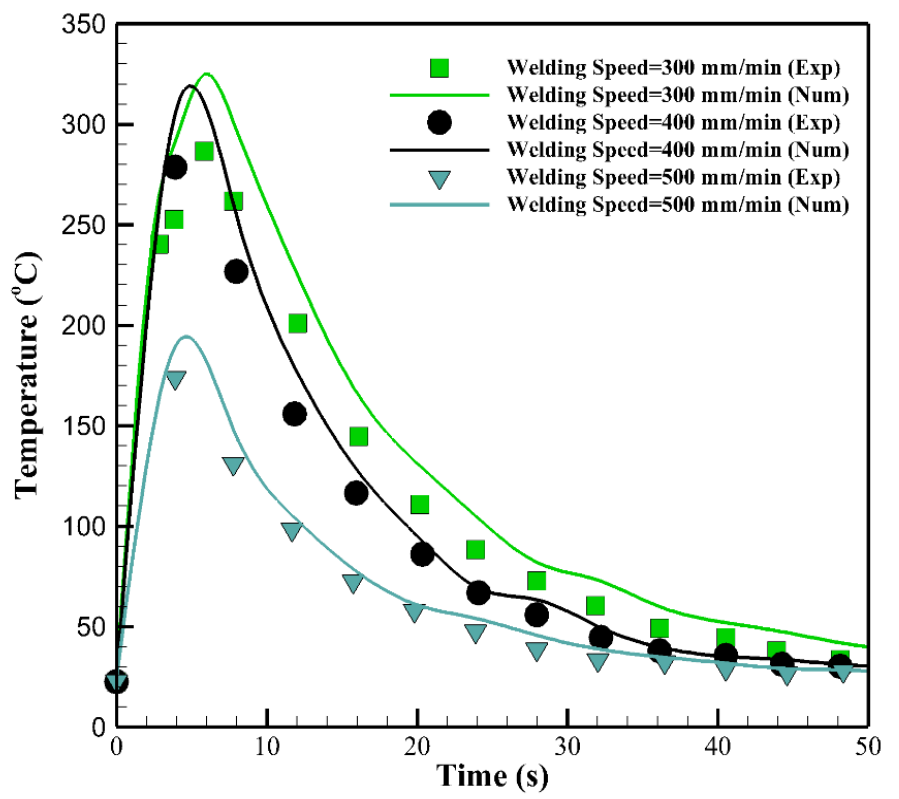

Fig. 4. Comparison of temperature distribution versus time in simulated and experimental results for different welding speeds.

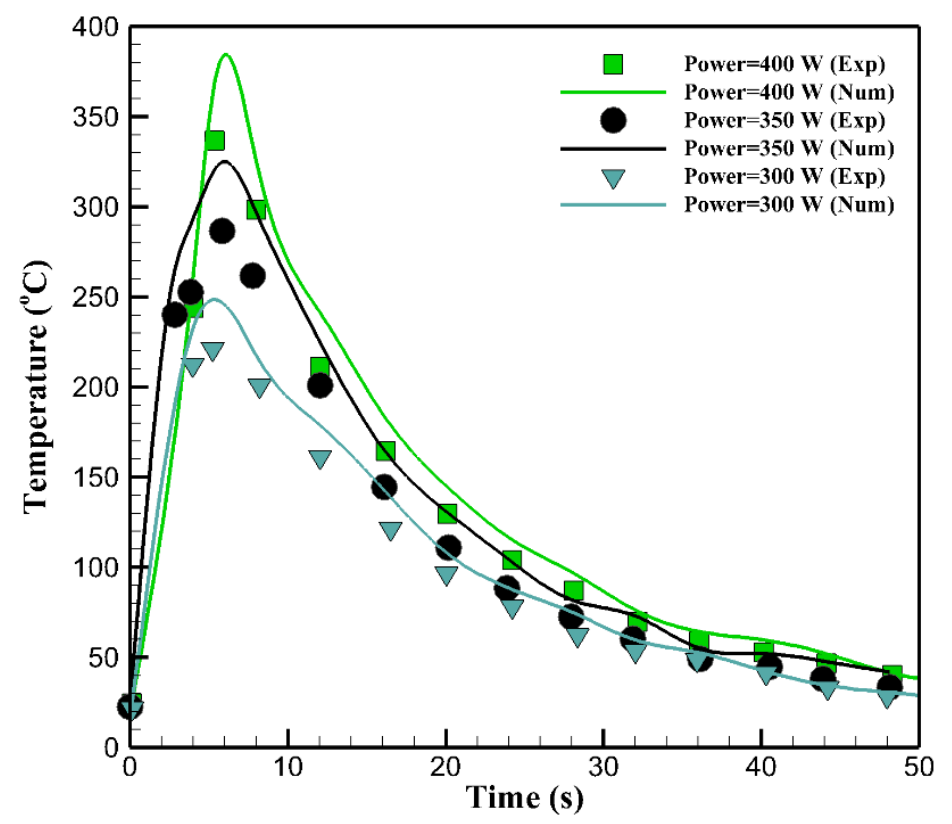

Fig. 5. Comparison of temperature distribution versus time in simulated and experimental results for different laser powers. 
Considering that there is no change in the microstructure of Inconel 625 alloy up to a temperature of $700{ }^{\circ} \mathrm{C}$ and the starting the formation of $\gamma(\mathrm{Ni3Nb})$ from $700{ }^{\circ} \mathrm{C}$; by determining the temperature distribution on the workpiece's surface, the range of the HAZ can be identified. Fig. 6 illustrates that the temperature contour at different welding speeds on the workpiece's surface. As can be seen, as the speed of movement of the thermal model increased due to the reduction of heat energy absorption time, the heat penetration to the around decreased. In other words, as the welding speed increased, the isothermal line became an ellipsoid shape which led to a reduction in the HAZ and liquid volume of metal. Fig. 7 indicated the effect of laser power on the sheet surface at a distance of $25 \mathrm{~mm}$ from the beginning of the welding. Because the thermal conductivity coefficient of Inconel 625 is relatively low, this caused less heat penetration to other parts of the workpiece. On the other hand, the HAZ was increased because the heat concentration was higher in the areas close to the laser beam. As shown in fig. 7, increasing the continuous laser power has no effect on the shape of the temperature field, and only the workpiece experienced a higher constant temperature line. 

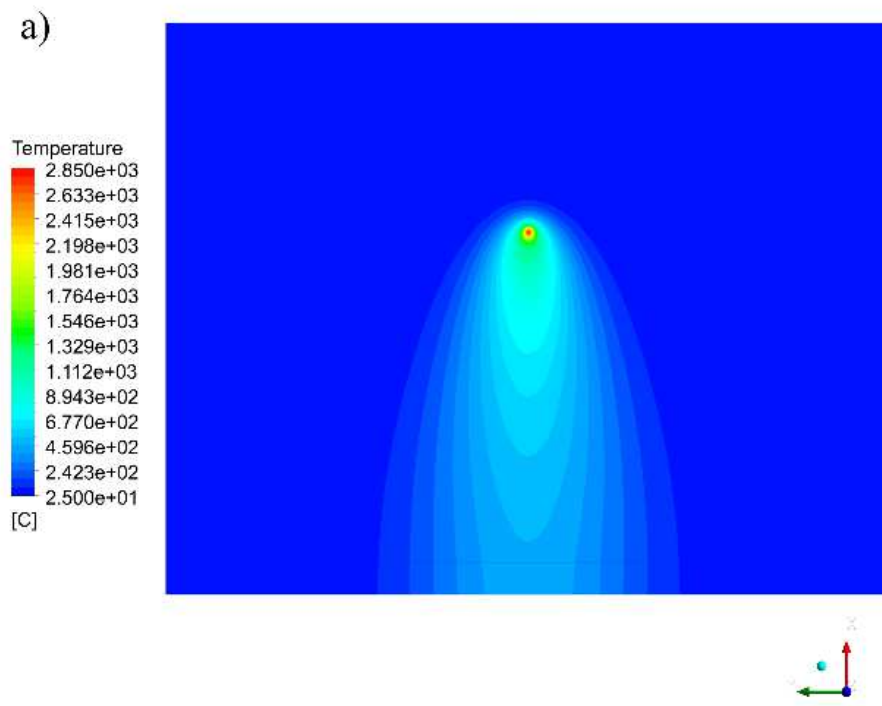

b)

c)

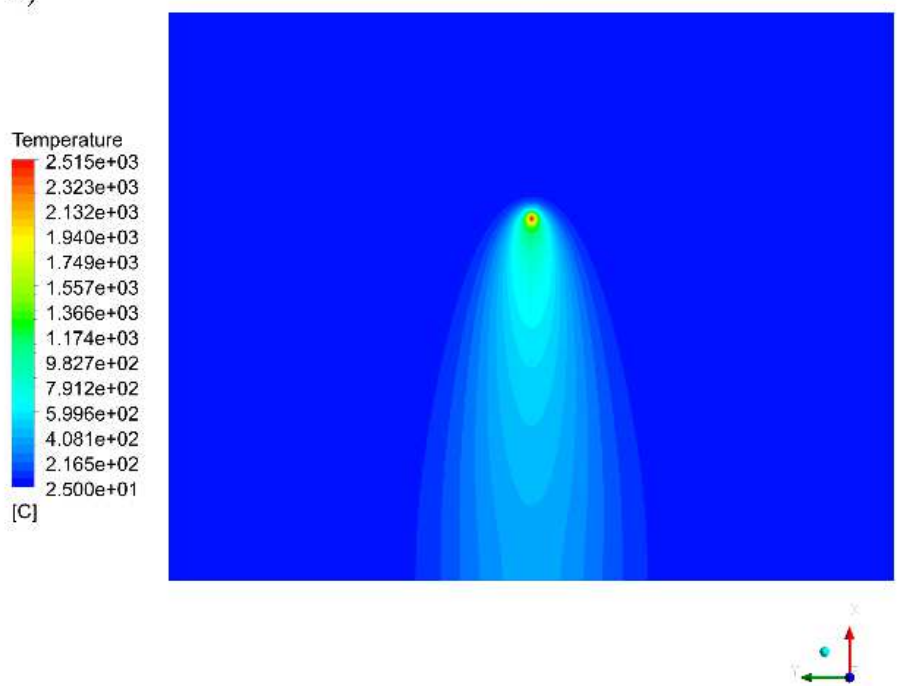

Fig. 6. Temperature contour on the workpiece's surface at different welding speeds, a) $300 \mathrm{~mm} / \mathrm{min}$, b) $400 \mathrm{~mm} / \mathrm{min}$, and c) $500 \mathrm{~mm} / \mathrm{min}$. 

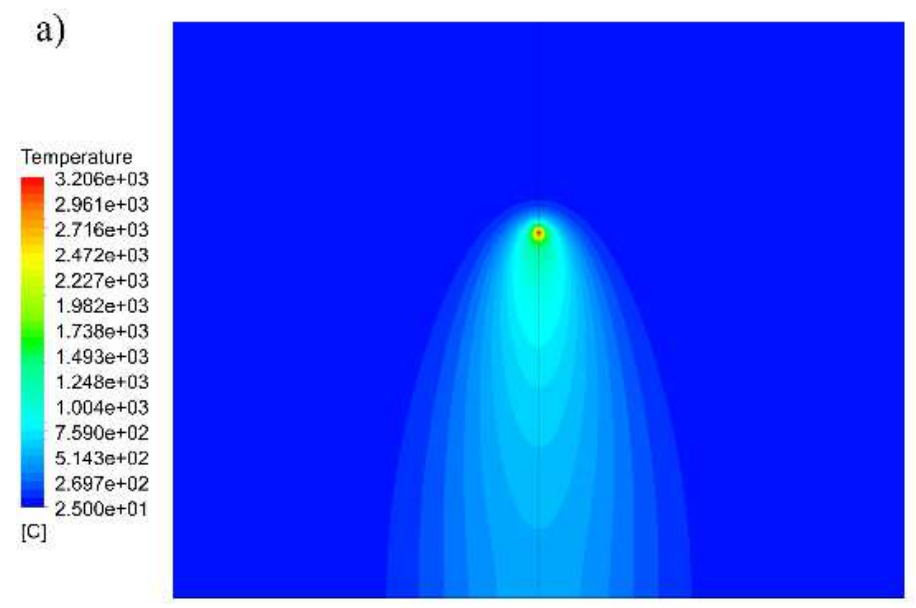

b)

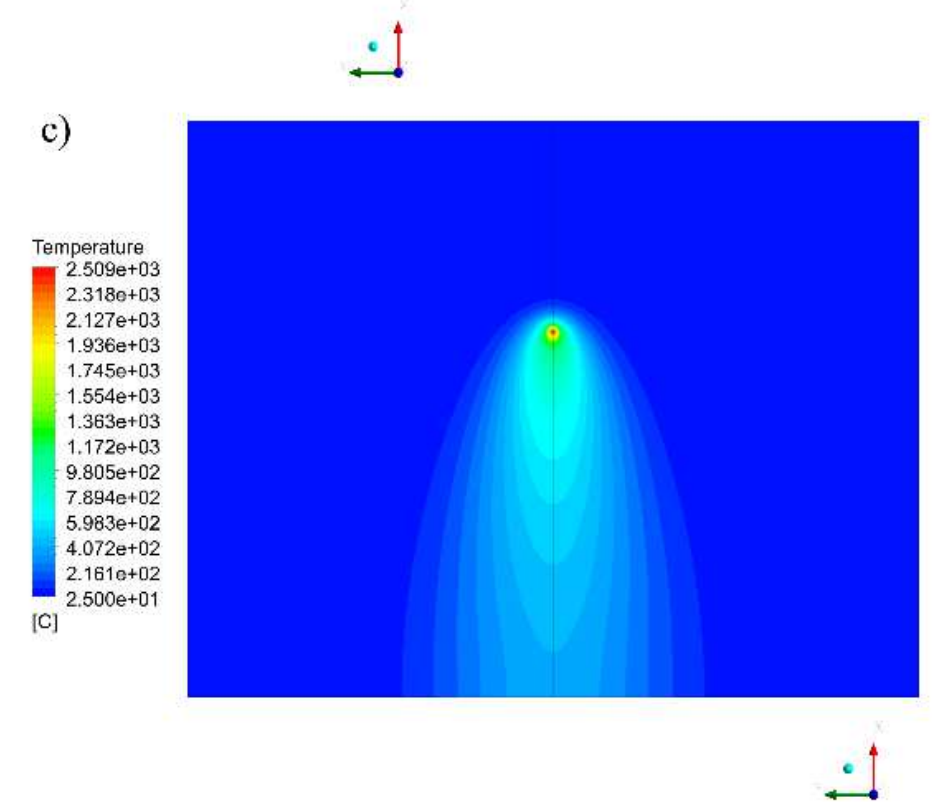

Fig. 7. Temperature contour on the workpiece's surface at various laser powers, a) $400 \mathrm{~W}$, b) $350 \mathrm{~W}$, and c) $300 \mathrm{~W}$.

\subsection{Velocity distribution}

Due to the active elements in the metals, their surface tension may increase or decrease at the molten pool's surface with increasing temperature. So that if the surface tension gradient was negative, the flow would move from the high-temperature region to the low-temperature region, and a Marangoni flow will be formed. Inconel alloy is one of the metals that has a negative Marangoni coefficient. As can be seen in figs. 8 and 9, the flow has been created across the cross- section of the workpiece from the laser beam's center to the mushy zone. 
Fig. 8 showed that with increasing the speed due to decreasing temperature and Marangoni force on the workpiece's surface, shear stress decreased, which led to a decrease in molten flow velocity. Fig. 9 indicated the vector of velocity in various continuous wave laser powers. As the laser power increased, due to the enhance of temperature gradient and surface tension gradient, the velocity of the molten flow increased and led to an increase in the role of convective heat transfer in the molten pool.
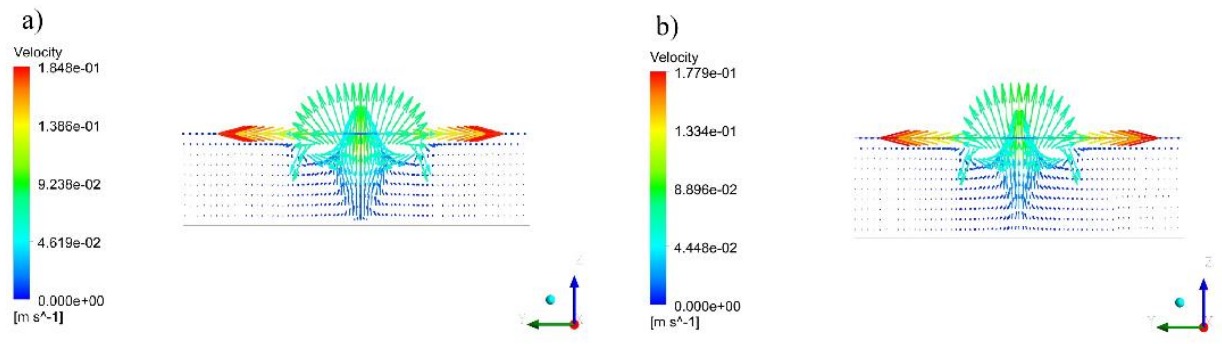

c)
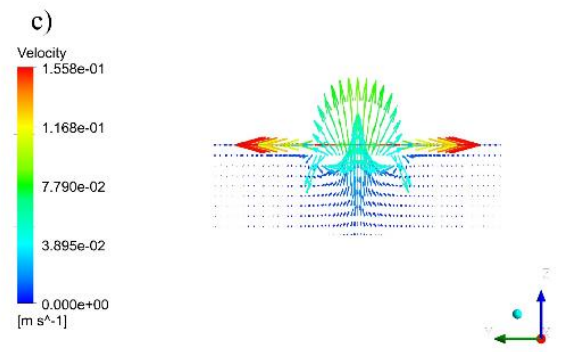

Fig. 8. Vector of velocity at the cross-section of the workpiece at various welding speeds, a) $300 \mathrm{~mm} / \mathrm{min}$, b) $400 \mathrm{~mm} / \mathrm{min}$, c) $500 \mathrm{~mm} / \mathrm{min}$. 

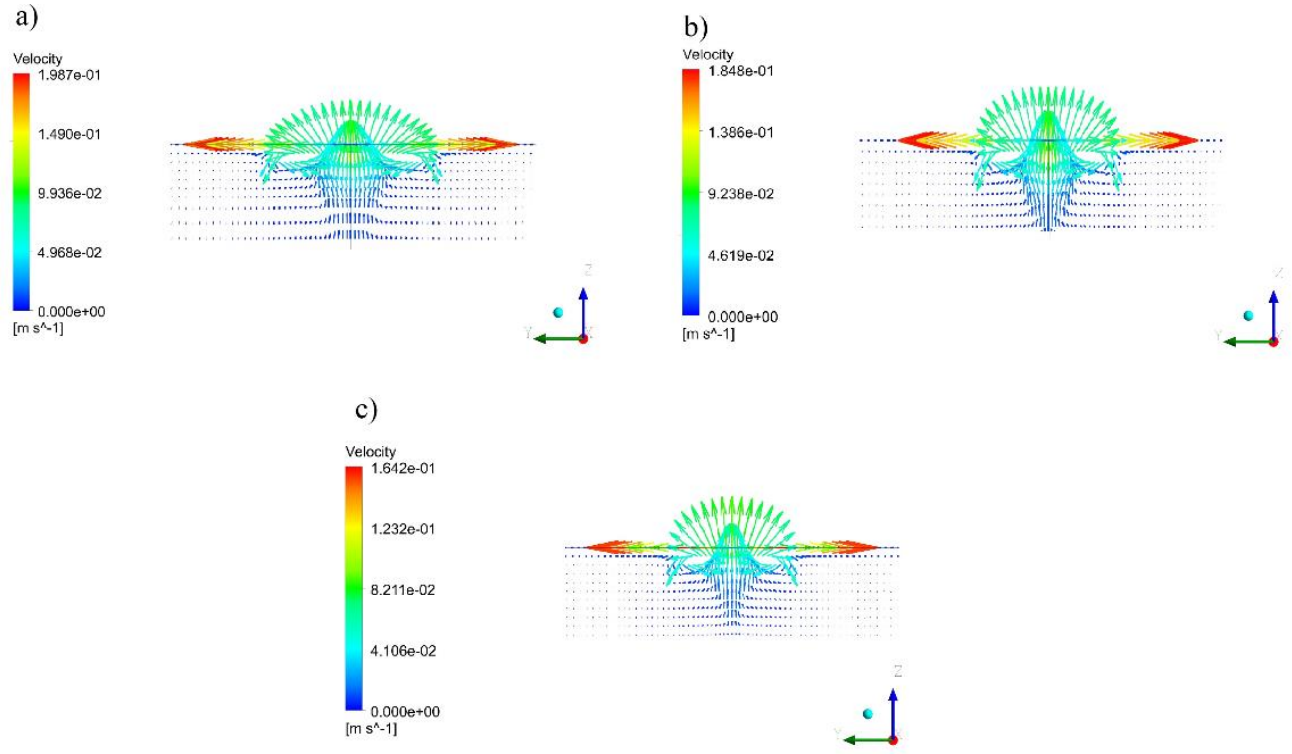

Fig. 9. Vector of velocity at the workpiece's cross-section at various laser powers, a) $400 \mathrm{~W}$, b) $350 \mathrm{~W}$, and c) $300 \mathrm{~W}$.

\subsection{Shape and dimensions of the molten pool}

Predicting the dimensions of the weld bead in different laser parameters can lead to the appropriate connection of the two sheets. Figs. 10 and 11 showed the mass fraction of the melt at different speeds of movement of the thermal model and laser powers, respectively. As seen in these figures, the amount of created melt was significantly reduced by increasing the speed and decreasing the laser power. In such a way that by enhancing the speed up to $500 \mathrm{~mm} / \mathrm{min}$, the melt has not penetrated to the depth of the workpiece. A comparison of the simulation results with the experimental results can be seen in Figure 12. At a speed of $300 \mathrm{~mm} / \mathrm{min}$, the penetration depth of the molten pool was created completely (figs. 12a and 12b), and as the welding speed enhanced, the molten pool's depth and width decreased simultaneously (figs. 12c and 12d). Fig. 13 indicated the changes in the width of the molten pool concerning the different welding speeds and laser powers. It can be seen that the laser power variations had a more significant effect on the width of the weld bead. 
a)

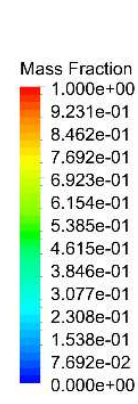

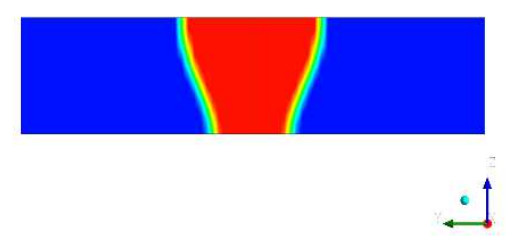

c) b)

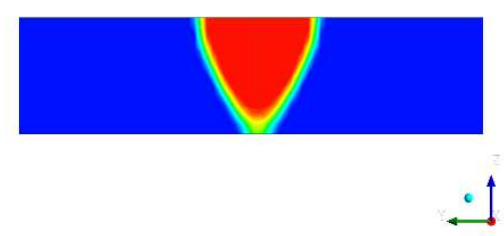

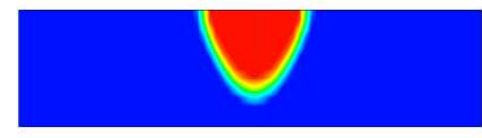

$\underset{0.500}{0.000} \underbrace{2.000(\mathrm{~mm})}_{1.500}$

Fig. 10. The molten pool's shape at various welding speeds, a) $300 \mathrm{~mm} / \mathrm{min}$, b) $400 \mathrm{~mm} / \mathrm{min}$, and c) 500 $\mathrm{mm} / \mathrm{min}$.

a)

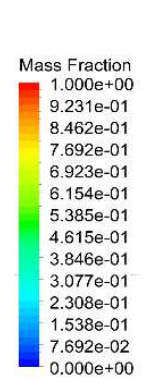

b)

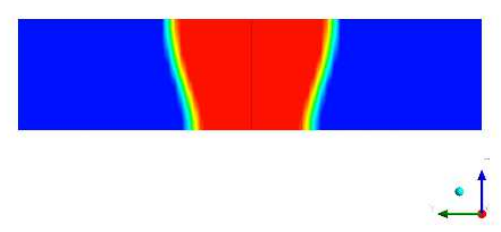

c)

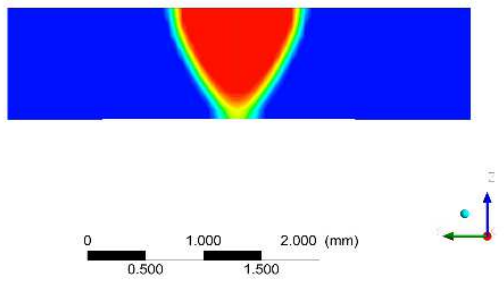

Fig. 11. The molten pool's shape at various laser powers, a) $400 \mathrm{~W}$, b) $350 \mathrm{~W}$, and c) $300 \mathrm{~W}$. 
a)

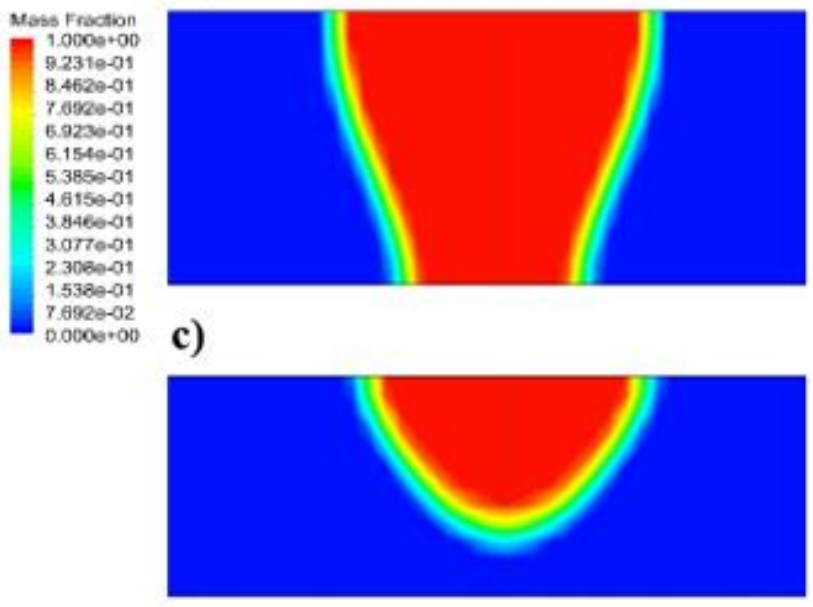

b)

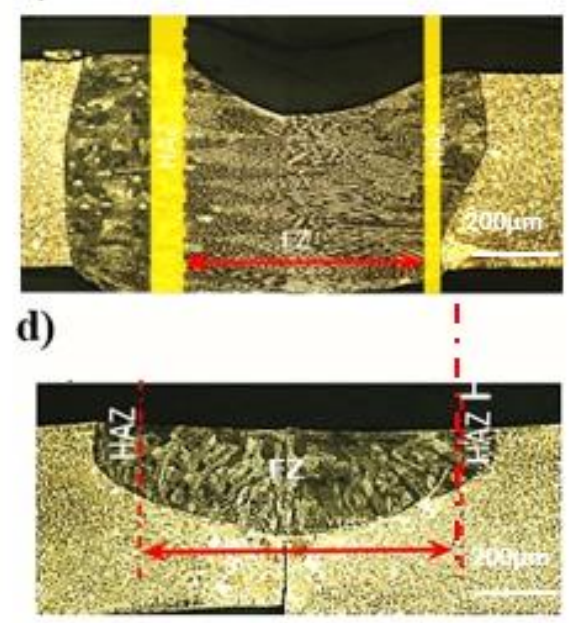

Fig. 12. Comparison of simulation results at welding speeds of a) $300 \mathrm{~mm} / \mathrm{min}$ and c) $500 \mathrm{~mm} / \mathrm{min}$ and experimental results of b) $300 \mathrm{~mm} / \mathrm{min}$ and d) $500 \mathrm{~mm} / \mathrm{min}$ for melt pool dimensions.

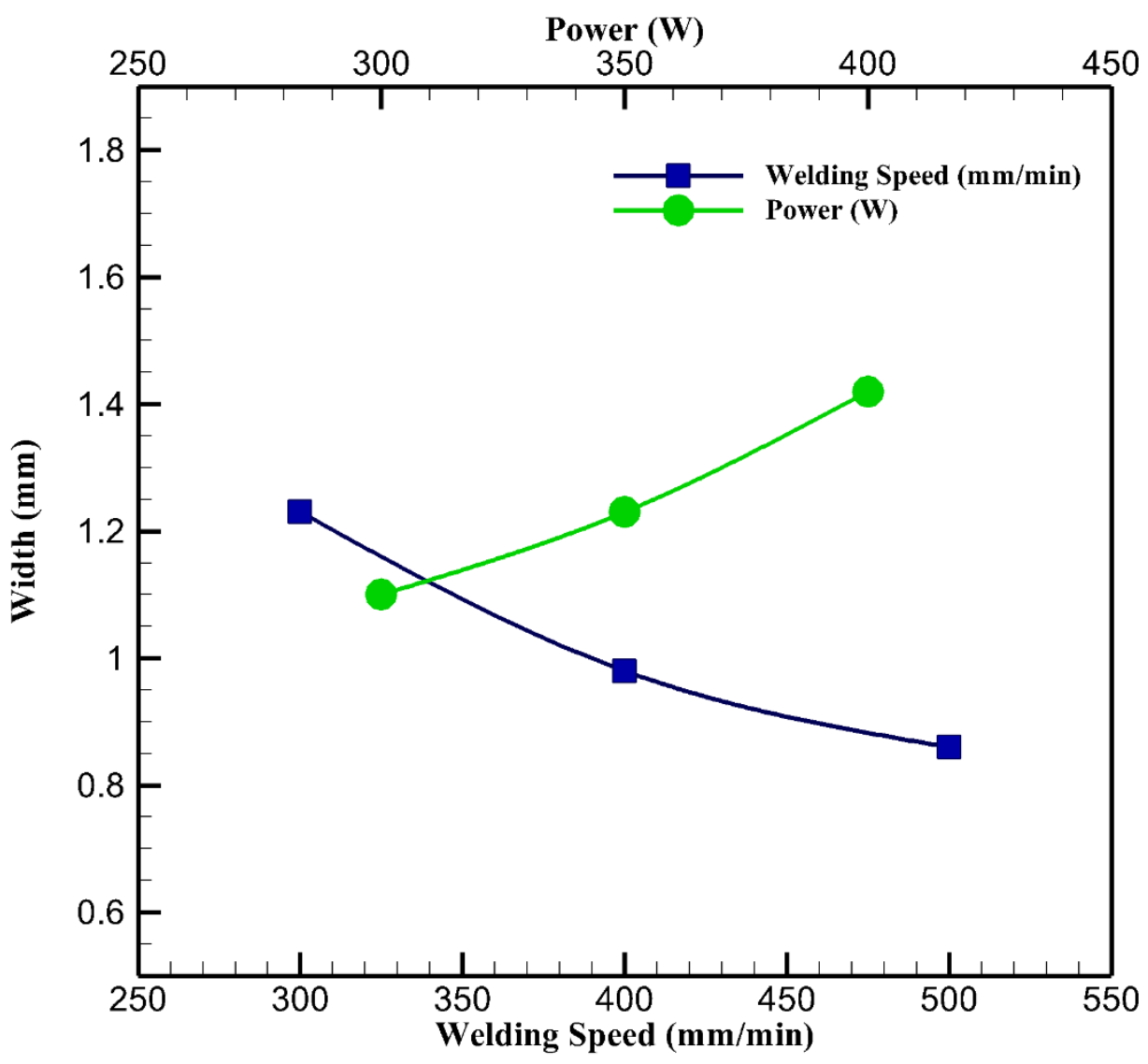

Fig. 13. The molten pool's width versus welding speed and laser power. 


\subsection{Microstructural changes of the molten pool}

Figure 14 showed the variation of microstructure from the base metal to the fusion zone due to changes in a temperature gradient. As can be seen in this figure, with increasing the temperature from $700{ }^{\circ} \mathrm{C}$ to the range of 1200 and $1800{ }^{\circ} \mathrm{C}$, microstructural changes have occurred from the base metal to the HAZ region, resulting in the formation of the austenitic coarse-grained structure relative to the base metal austenitic structure. With further increase in temperature in the molten pool to $3200{ }^{\circ} \mathrm{C}$, the shape, size, and direction of the grains in this area have changed completely. The shape and size of the grains and the microstructure change in the molten pool area consisted of a $\gamma$ solid solution which increased in hardness in this area due to the intense thermal gradient. Thus, the melting of the material has led to forming a new microstructure in the fusion zone.

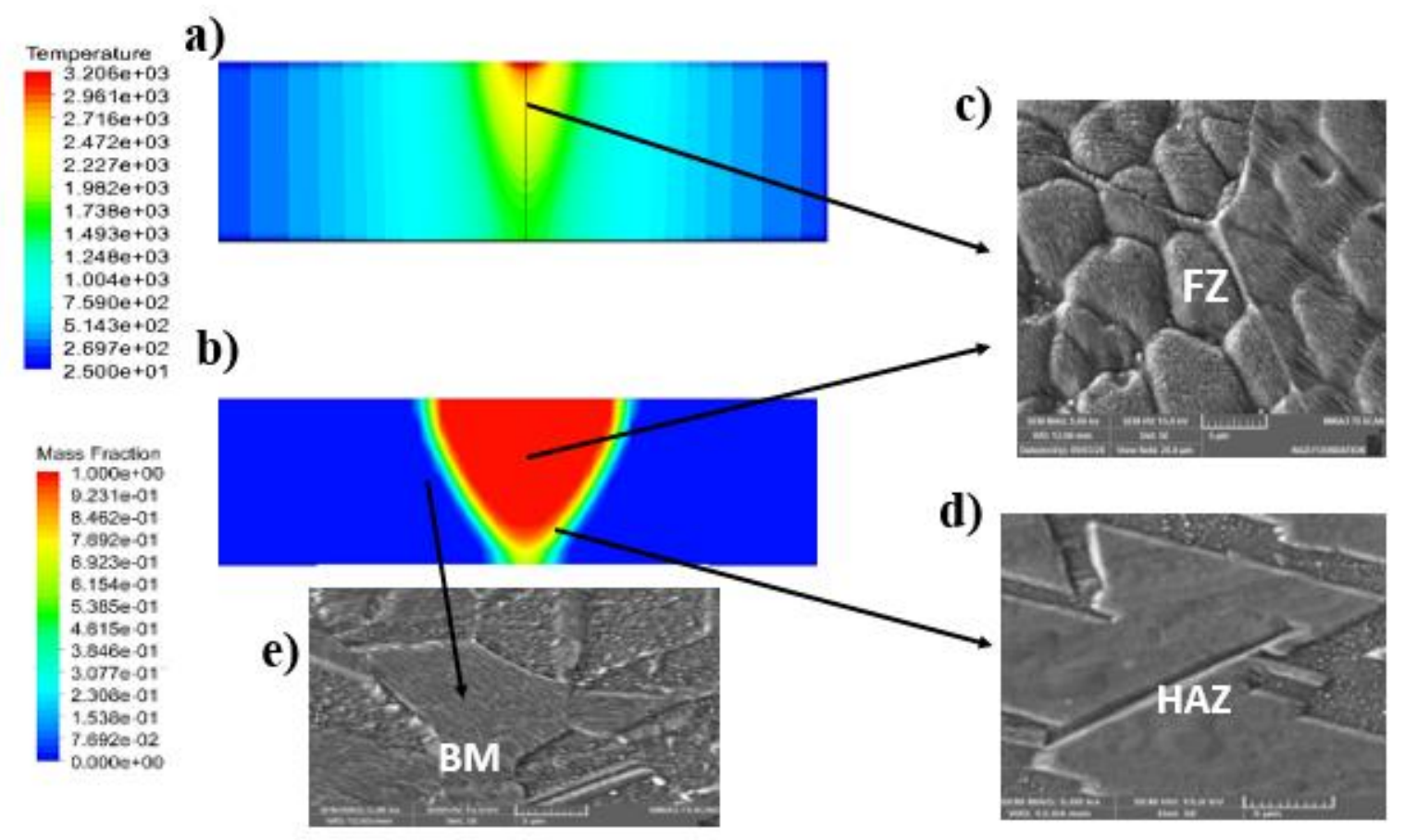

Fig. 14. Microstructural changes with temperature gradients in the molten pool area, temperature distribution (simulation), b) melting flow (simulation), c) molten pool microstructure (experiment), d) HAZ microstructure (experiment), and e) base metal microstructure (experiment).

\section{Conclusions}


In this study, the welding speed and laser power effects during the continuous wave laser welding process of the Inconel 625 sheet were investigated by finite volume and experimental methods. In order to model the energy absorbed in the workpiece, surface and volumetric heat flux were used. Also, due to the high-temperature gradient during the welding process, the thermal conductivity, density, and specific heat capacity were defined as a function of temperature. The results are as follows:

- By enhancing the laser power from 300 to $400 \mathrm{~W}$, the peak temperature in the laser beam's center at $25 \mathrm{~mm}$ from the beginning of the workpiece increased to $697{ }^{\circ} \mathrm{C}$. The simulation results also showed that reducing the laser power to $300 \mathrm{~W}$ led to no penetration of the melt into the depth of the workpiece.

- As the welding speed increased, the constant temperature lines on the surface of the part became ellipsoid which led to a decrease in the HAZ and the melting ratio.

- Marangoni flow played a key role in determining the shape and dimensions of the molten pool so that by reducing the welding speed to $200 \mathrm{~mm} / \mathrm{min}$, the melt flow rate increased by $29 \mathrm{~mm} / \mathrm{s}$.

- By increasing the temperature from $700{ }^{\circ} \mathrm{C}$ to the range of 1200 and $1800{ }^{\circ} \mathrm{C}$, microstructural changes have occurred from the base metal to the HAZ region, resulting in the formation of the austenitic coarse-grained structure relative to the base metal austenitic structure.

\section{Declarations}

Funding Dr. Iskander Tlili would like to thank Deanship of Scientific Research at Majmaah University for supporting this work under the Project Number No. 134325.

Conflicts of interest The authors declare no conflicts of interests.

Availability of data and material The raw/processed data required to reproduce these findings cannot be shared at this time due to technical or time limitations.

Code availability Not applicable. 
Ethics approval Not applicable.

Consent to participate Not applicable.

Consent for publication Not applicable.

Author contribution Tlili, Sajadi, and Ghaemi conducted methodology, software and validation; Baleanu and Sajadi conducted the experimental test and analysis of the data; Tlili, Baleanu and Ghaemi wrote the paper.

\section{References}

[1] X. Meng, A. Artinov, M. Bachmann, and M. Rethmeier, "Theoretical study of influence of electromagnetic stirring on transport phenomena in wire feed laser beam welding," Journal of Laser Applications, vol. 32, no. 2, p. 022026, 2020.

[2] G. Shanthos Kumar, S. Saravanan, R. Vetriselvan, and K. Raghukandan, "Numerical and experimental studies on the effect of varied pulse energy in Nd:YAG laser welding of Monel 400 sheets," Infrared Physics \& Technology, vol. 93, pp. 184-191, 2018/09/01/ 2018.

[3] A. I. Khdair, M. Hader, K. Abushgair, and S. Khrais, "Effect of sheet thickness on the fusion zone temperature distribution, melt pool dimensions, mechanical properties, and microstructure in laser welding of Ti6Al4V alloy," Journal of Laser Applications, vol. 33, no. 3, p. 032005, 2021.

[4] X. Hu, Z. Xue, G. Zhao, J. Yun, D. Shi, and X. Yang, "Laser welding of a selective laser melted Ni-base superalloy: Microstructure and high temperature mechanical property," Materials Science and Engineering: A, vol. 745, pp. 335-345, 2019/02/04/ 2019.

[5] Y. Chen, K. Zhang, J. Huang, S. R. E. Hosseini, and Z. Li, "Characterization of heat affected zone liquation cracking in laser additive manufacturing of Inconel 718," Materials \& Design, vol. 90, pp. 586-594, 2016/01/15/ 2016.

[6] W. Liu, F. Lu, R. Yang, X. Tang, and H. Cui, "Gleeble simulation of the HAZ in Inconel 617 welding," Journal of Materials Processing Technology, vol. 225, pp. 221-228, 2015/11/01/ 2015. 
[7] Z. Tian et al., "A Review on Laser Powder Bed Fusion of Inconel 625 Nickel-Based Alloy," Applied Sciences, vol. 10, no. 1, p. 81, 2020.

[8] Y. Yongbin, S. A. Bagherzadeh, H. Azimy, M. Akbari, and A. Karimipour, "Comparison of the artificial neural network model prediction and the experimental results for cutting region temperature and surface roughness in laser cutting of AL6061T6 alloy," Infrared Physics \& Technology, vol. 108, p. 103364, 2020/08/01/ 2020.

[9] H. Heydari and M. Akbari, "Investigating the effect of process parameters on the temperature field and mechanical properties in pulsed laser welding of Ti6Al4V alloy sheet using response surface methodology," Infrared Physics \& Technology, vol. 106, p. 103267, 2020/05/01/ 2020 .

[10] C. Wang, H. Liu, Z. Chen, D. Zhao, and C. Wang, "A new finite element model accounting for thermal contact conductance in laser transmission welding of thermoplastics," Infrared Physics \& Technology, vol. 112, p. 103598, 2021/01/01/ 2021.

[11] M. Azari, E. Rasti, M. H. R. Dehkordi, H. Azimy, A. Zarei, and S. A. Bagherzadeh, "Investigation of temperature distribution and melt pool microstructure in laser fusion welding of Inconel 625 superalloy," Journal of Laser Applications, vol. 33, no. 2, p. 022015, 2021.

[12] A. H. Faraji, C. Maletta, G. Barbieri, F. Cognini, and L. Bruno, "Numerical modeling of fluid flow, heat, and mass transfer for similar and dissimilar laser welding of Ti-6Al-4V and Inconel 718," The International Journal of Advanced Manufacturing Technology, vol. 114, no. 3, pp. 899-914, 2021/05/01 2021.

[13] S. Madhankumar et al., "Experimental investigation on ultimate tensile strength of laser butt welded inconel 718 alloy and 2205 duplex stainless steel," Materials Today: Proceedings, vol. 45, pp. 6783-6787, 2021/01/01/2021.

[14] P. Thejasree, N. Manikandan, J. S. Binoj, K.C.Varaprasad, D. Palanisamy, and R. Raju, "Numerical simulation and experimental investigation on laser beam welding of Inconel 625," Materials Today: Proceedings, vol. 39, pp. 268-273, 2021/01/01/ 2021.

[15] G. N. Ahmad, M. S. Raza, N. K. Singh, and H. Kumar, "Experimental investigation on Ytterbium fiber laser butt welding of Inconel 625 and Duplex stainless steel 2205 thin sheets," Optics \& Laser Technology, vol. 126, p. 106117, 2020/06/01/ 2020. 
[16] A. Voropaev, M. Stramko, A. Sorokin, I. Logachev, M. Kuznetsov, and S. Gook, "Laser welding of Inconel 718 nickel-based alloy layer-by-layer products," Materials Today: Proceedings, vol. 30, pp. 473-477, 2020/01/01/ 2020.

[17] S. Srikanth and A. Parthiban, "Microstructural analysis of Nd:YAG laser welding for Inconel alloy," Materials Today: Proceedings, vol. 21, pp. 568-571, 2020/01/01/ 2020.

[18] M. Cheepu, Y. A. Kumar Reddy, S. Indumathi, and D. Venkateswarlu, "Laser welding of dissimilar alloys between high tensile steel and Inconel alloy for high temperature applications," Advances in Materials and Processing Technologies, pp. 1-12, 2020.

[19] S. K. Sharma, K. Biswas, A. K. Nath, I. Manna, and J. Dutta Majumdar, "Microstructural change during laser welding of Inconel 718," Optik, vol. 218, p. 165029, 2020/09/01/ 2020.

[20] D. R. K, D. Sidharth, P. P. K.V, R. R, G. M. K, and N. S, "Microstructure and properties of inconel 718 and AISI 416 laser welded joints," Journal of Materials Processing Technology, vol. 266, pp. 52-62, 2019/04/01/ 2019.

[21] A. Mishra, D. Dixit, and A. K. Sharma, "Study on microstructural and mechanical properties of dissimilar joint of laser beam welded Inconel 625 and SS 316," Int J Eng Adv Technol, vol. 6, no. 1, pp. 1-20, 2018.

[22] L. Li, G. Peng, J. Wang, J. Gong, and H. Li, "Experimental study on weld formation of Inconel 718 with fiber laser welding under reduced ambient pressure," Vacuum, vol. 151, pp. 140-147, 2018/05/01/2018.

[23] I. Hernando, J. I. Arrizubieta, A. Lamikiz, and E. Ukar, "Numerical Model for Predicting Bead Geometry and Microstructure in Laser Beam Welding of Inconel 718 Sheets," Metals, vol. 8, no. 7, p. 536, 2018.

[24] I. Hernando, M. A. Renderos, M. Cortina, J. E. Ruiz, J. I. Arrizubieta, and A. Lamikiz, "Inconel 718 laser welding simulation tool based on a moving heat source and phase change," Procedia CIRP, vol. 74, pp. 674-678, 2018/01/01/ 2018.

[25] M. R. Jelokhani-Niaraki, N. B. Mostafa Arab, H. Naffakh-Moosavy, and M. Ghoreishi, "The systematic parameter optimization in the Nd:YAG laser beam welding of Inconel 625," The International Journal of Advanced Manufacturing Technology, vol. 84, no. 9, pp. 2537-2546, 2016/06/01 2016. 
[26] A. N. Ebrahimi, N. B. M. Arab, and M. H. Gollo, "Thermal analysis of laser beam welding of nickel-based super alloy Inconel 625 to AISI 316L, using Gaussian optics theory in keyhole," Journal of the Brazilian Society of Mechanical Sciences and Engineering, vol. 38, no. 4, pp. 1199-1206, 2016/04/01 2016.

[27] S. Janasekaran, A. W. Tan, F. Yusof, and M. H. Abdul Shukor, "Influence of the Overlapping Factor and Welding Speed on T-Joint Welding of Ti6A14V and Inconel 600 Using Low-Power Fiber Laser," Metals, vol. 6, no. 6, p. 134, 2016.

[28] W. Ren, F. Lu, R. Yang, X. Liu, Z. Li, and S. R. Elmi Hosseini, "A comparative study on fiber laser and CO2 laser welding of Inconel 617," Materials \& Design, vol. 76, pp. 207$214,2015 / 07 / 05 / 2015$.

[29] Singh R, Alberts MJ, Melkote SN. Characterization and prediction of the heat-affected zone in a laser-assisted mechanical micromachining process. International Journal of Machine Tools and Manufacture. 2008 Jul 1;48(9):994-1004.

[30] Xia P, Yan F, Kong F, Wang C, Liu J, Hu X, Pang S. Prediction of weld shape for fiber laser keyhole welding based on finite element analysis. The International Journal of Advanced Manufacturing Technology. 2014 Oct 1;75(1-4):363-72.

[31] R. Ducharme, P. Kapadia, and J. Dowden, "A mathematical model of the defocusing of laser light above a workpiece in laser material processing," Int. Congr. Appl. Lasers Electro Opt. 1992, 187-197 (1992).

[32] K. Abderrazak, S. Bannour, H. Mhiri, G. Lepalec, and M. Autric, "Numerical and experimental study of molten pool formation during continuous laser welding of AZ91magnesium alloy," Comput. Mater. Sci. 44, 858-866 (2009).

[33] Kundakcioğlu E, Lazoglu I, Poyraz Ö, Yasa E, Cizicioğlu N. Thermal and molten pool model in selective laser melting process of Inconel 625. The International Journal of Advanced Manufacturing Technology. 2018 Apr;95(9):3977-84.

[34] Kaschnitz E, Kaschnitz L, Heugenhauser S. Electrical resistivity measured by millisecond pulse heating in comparison with thermal conductivity of the superalloy Inconel 625 at elevated temperature. International Journal of Thermophysics. 2019 Mar 1;40(3):27. 
[35] O'Flynn J, Whitman CA, Corbin SF. Thermal property measurements of metal injection moulded Inconel 625 and Inconel 718 using combined thermal analysis techniques. Powder Metallurgy. 2020 Aug 7;63(4):277-87.

[36] Wang Z, Denlinger E, Michaleris P, Stoica AD, Ma D, Beese AM. Residual stress mapping in Inconel 625 fabricated through additive manufacturing: Method for neutron diffraction measurements to validate thermomechanical model predictions. Materials \& Design. 2017 Jan 5;113:169-77.

[37] Özel T, Arısoy YM, Criales LE. Computational simulation of thermal and spattering phenomena and microstructure in selective laser melting of inconel 625. Physics Procedia. 2016 Jan 1;83:1435-43.

[38] Mills KC. Recommended values of thermophysical properties for selected commercial alloys. Woodhead Publishing; 2002.

[39] Valencia JJ, Quested PN. Thermophysical properties.

[40] Indhu R, Vivek V, Sarathkumar L, Bharatish A, Soundarapandian S. Overview of laser absorptivity measurement techniques for material processing. Lasers in Manufacturing and Materials Processing. 2018 Dec;5(4):458-81. 